\title{
Retrospective Review
}

\section{Patient Selection and Outcomes Using a Low- Dose Intrathecal Opioid Trialing Method for Chronic Nonmalignant Pain}

Jay S. Grider, DO, PhD, Michael E. Harned, MD, and Mark A. Etscheidt, PhD

\begin{abstract}
From: University of Kentucky, Lexington, $\mathrm{KY}$.

Dr. Grider is Associate Professor, Department of Anesthesiology, University of Kentucky, Lexington,

Dr. Harned and Dr. Etscheidt are both with the Department of Anesthesiology, University of Kentucky, Lexington, $\mathrm{KY}$

Address correspondence: Jay S. Grider, DO, PhD Department of Anesthesiology University of Kentucky 800 Rose Street

$\mathrm{N}-201$ Chandler Medical Center Lexington, $\mathrm{KY}$

E-mail:jsgrid2@email.uky.edu

Disclaimer: There was no external funding in the preparation of this manuscript.

Conflict of interest: None.
\end{abstract}

Manuscript received: 03/25/2011 Accepted for publication: 05/13/2011

Free full manuscript: www.painphysicianjournal.com
Background: Various methods exist for trialing patients for intrathecal drug delivery. Currently no standards exist regarding "best practices" for trialing techniques.

Objectives: The specific aim of the current study is to report results of patients trialed using a low-dose intrathecal morphine technique in the treatment of chronic noncancer pain.

Setting: academic pain medicine practice

Study Design: Retrospective Review

Method: Visual analog pain scores (VAS) were obtained at the initial visit, after a 6 week opioid-free interval prior to trial, at intrathecal doses of 25,50, 100, 200 and $400 \mu \mathrm{g}$ of intrathecal morphine during the trial, at one month post-implant, and current VAS. Additionally, intrathecal opioid doses at implant and current state are reported.

Results: VAS scores at the initial visit and after 6 weeks of opioid cessation were identical. There was a significant improvement in VAS after the trial, which was sustained over the course of therapy. Additionally, the use of the protocol described in this article suggests that the doseresponse relationship following opioid cessation is in the $50-400 \mu \mathrm{g} / \mathrm{d}$ range for intrathecal morphine and that tolerance may be reversed during the 6 week opioid-free period.

Limitations: Small trialing study

Conclusions: Opioid taper and a 6 week opioid-free period may 1) improve long-term analgesia versus a combination of oral/ intrathecal drug delivery system therapy 2 ) it may be possible to maintain analgesia at microgram doses and 3) opioid tolerance may be reversible in 6 weeks. Further it appears that a dose response relationship for effective analgesia may be less than $400 \mu \mathrm{g}$ of intrathecal morphine.

Key Words: Intrathecal opioids, intrathecal drug delivery, oral opioid therapy, chronic noncancer pain

Pain Physician 2011; 14:343-351 se of an implanted intrathecal drug delivery system (IDDS) in the treatment of intractable chronic pain has been a valuable therapeutic modality over the last 3 decades (1). While first described in the treatment of cancer-related pain, intrathecal drug therapy (IDT) has been utilized for various noncancer disease states. Patients with poorly controlled pain associated with failed back surgery syndrome, complex regional pain syndrome, spinal stenosis, vertebral compression fractures, and peripheral limb pain have benefited from use of an IDDS when other less invasive measures have failed 
(2). While the use of IDT for chronic noncancer pain has increased over the past 3 decades, there has been relatively little literature available to guide the clinician with regard to patient selection, trialing method, and ultimately, initial starting dose of the intrathecally applied drug.

A recent consensus guideline has filled the void of a comprehensive dialogue with regard to patient selection, and has made recommendations for best practices with regard to trialing techniques for those with noncancer pain (2). Likewise, the polyanalgesic consensus panel clearly outlined from an evidence-based perspective how different drugs should be utilized in an IDDS (3). While these documents represent a major advance toward the goal of establishing best practices with regard to this therapy, several questions remain. For instance, most patients with intractable pain who are deemed to be candidates for an IDDS present on oral opioid therapy with diminishing results. As such, should oral opioids be continued, reduced, or even eliminated? Establishing appropriate starting doses for an intrathecal trial in such patients is likewise based upon clinical experience and estimation. Further, to our knowledge the dose-response relationships for intrathecal opioids have not been established in humans.

With regard to trialing techniques, we have recently reported the outcomes of 2 patients identified and trialed using a clinical protocol established previously within our center (4). This protocol utilizes an opioid taper and subsequent application of microgram dosing of intrathecal opioid with sustained efficacy. This concept was first articulated for mass distribution in a best practices publication by Witt and Richardson (5). In both reports, patients initially screened and deemed to be candidates for IDT underwent a reduction or elimination in oral opioid therapy and subsequently had an IDDS implanted with better-improved efficacy and stabilization of pain. In the current study, we describe a low-dose intrathecal trialing protocol and outcomes in patients presenting with intractable chronic pain who have failed conservative therapy.

\section{Methods}

A retrospective review of outcomes in 22 consecutive patients evaluated and deemed to be candidates for intrathecal therapy in an academic Pain Medicine practice utilizing a low-dose intrathecal opioid protocol for inpatient trialing is presented. An Institutional Review Board (IRB) approved this retrospective review. The reported results are from all patients trialed using this protocol in a 36 month period. Ten patients had a diagnosis of Failed Back Surgery Syndrome with spinal fusion being most common (7/10); laminectomy alone (2/10); one patient failed 2 microdiscectomies. Six patients had spinal stenosis, which was deemed nonoperable, while 2 had scoliosis and had failed to obtain acceptable analgesia with oral opioids. Three patients had degenerative disc disease and were intolerant to oral opioid therapy. One patient had Complex Regional Pain Syndrome Type 2 with a poor response to oral opioids. This patient previously had acceptable analgesia with spinal cord stimulation, but unfortunately this therapy failed after a lead fracture occurred. Attempts to regain stimulation by the implanting physician were unsuccessful according to the patient history

\section{Protocol}

Patients with chronic noncancer pain who have failed noninvasive therapy such as oral opioid treatment, injection therapy, rehabilitative physical therapy, and for whom there are no further surgical options, are deemed potential candidates for an IDDS. After careful review of the risks and benefits of IDT, the patient is evaluated by a behavioral psychologist. The multidisciplinary team then decides if the patient is appropriate for a trial of IDT. An approved candidate is then carefully tapered off oral opioids over a 3 to 4 week period and remains opioidfree for 5 weeks. During the taper and opioid-free period, the patient has liberal access to our behavioral medicine team; adjunctive medications such as nonsteroidal anti-inflammatory drugs (NSAIDs) and anticonvulsants are continued. At week 6, a pre-procedure functional evaluation is performed by an occupational therapist and physical therapist familiar with the protocol goals. Following intravenous antibiotic administration, an intrathecal catheter is placed under strict aseptic technique at the $L 4 / 5$ or $L 3 / 4$ level and the catheter is then passed under fluoroscopic guidance to the T11 vertebral level. The patient is then admitted to the hospital and an infusion is begun at $25 \mu \mathrm{g} / \mathrm{d}$ of intrathecal morphine at a concentration of $0.1 \mathrm{mg} / \mathrm{mL}$ of preservative-free morphine. American Society of Anesthesiologists guidelines (6) for monitoring of patients with neuraxial therapy are followed. Those with diagnosed obstructive sleep apnea or morbid obesity are continuously monitored with pulseoxemitry (7). The dose is titrated every 12 hours (Table 1) until pain relief is achieved or therapy-limiting side effects are identified.

Once efficacy is achieved, the patient remains on 
that dose for 24-36 hours and is evaluated for side effects and functional improvement with the IDT. If no issues are identified, the catheter is removed, the patient is instructed to lie flat for one hour and is then discharged home. Implantation in successful candidates occurs 10-14 days later to allow any complications of the catheter trial to be determined. Patients remain opioidfree during this period. Upon implantation, the patient is started at the effective trial dose and remains free of oral opioid therapy thereafter.

\section{Outcomes Assessments}

A pre-trial VAS (8) pain evaluation is obtained while the patient is still on opioid therapy. VAS scores are subsequently obtained following the six week opioid-free interval and following implementation of the IDT allowing comparison of patient reported pain scores on and off oral therapy.

The VAS measures patient-reported pain experiences allowing for intra-patient control comparisons. VAS scores during functional evaluation and at rest are also obtained and compared during the trialing phase by the occupational and physical therapists. VAS scores as reported are obtained by physicians during rounds and clinic visits.

\section{RESULTS}

Twenty-two patients were trialed using this protocol. Of those patients, ultimately 20 went on to have an
IDDS implanted. The 2 trial failures were secondary to urinary retention and not due to an intrinsic issue with the trialing protocol. Two patients did not receive desired efficacy with intrathecal morphine and were subsequently re-trialed with hydromorphone, ultimately achieving a satisfactory level of analgesia. The intrathecal dosages for these 2 patients were recorded in morphine equivalents for the purpose of data analysis.

\section{VAS before trial and after implant:}

Prior to the opioid taper, pain scores were reported as an average VAS of $7.3 \pm 1.9$. Pain scores on the day of admission after the 6 week opioid-free interval, but prior to intrathecal catheter placement, were $7.15 \pm 1.1$ On return to the clinic one week following implantation, the VAS was reported to be $3.1 \pm 2.4$. Since the duration of therapy varied, all patient VASs at 12 months were compared. At 12 months the VAS had marginally increased to $3.9 \pm 2.6$. The VAS did not

Table 1. Intrathecal protocol time course and dosing schedule.

\begin{tabular}{|l|l|}
\hline Trial Day $16 \mathrm{am}$ & $25 \mathrm{mcg} /$ day morphine \\
\hline Trial Day $16 \mathrm{pm}$ & $50 \mathrm{mcg} /$ day morphine \\
\hline Trial Day $26 \mathrm{am}$ & $100 \mathrm{mcg} /$ day morphine \\
\hline Trial Day $26 \mathrm{pm}$ & $200 \mathrm{mcg} /$ day morphine \\
\hline Trial Day $36 \mathrm{am}$ & $400 \mathrm{mcg} /$ day morphine \\
\hline
\end{tabular}

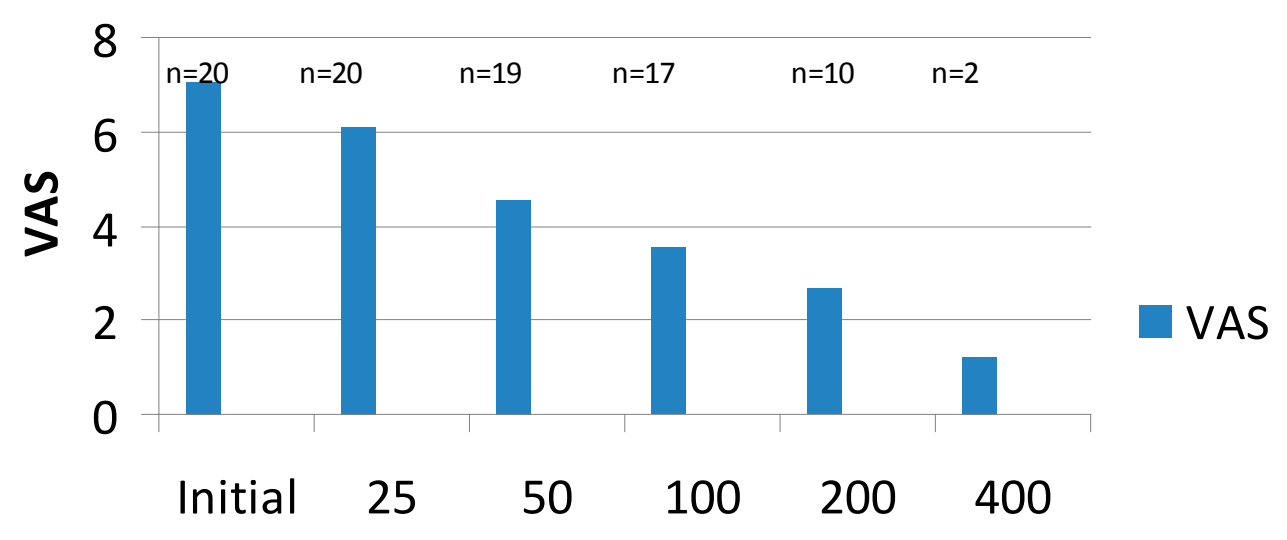

\section{$\mu \mathrm{g} / \mathrm{d}$ intrathecal morphine}

Fig. 1. Average VAS of all patients at each dosage of intrathecal morphine. When satisfactory analgesia was achieved, dose titration and VAS recording ceased, accounting for the decreasing number of patients. Satisfactory analgesia was considered to be achieved when a patient reported VAS was 3.5 or less and the patient satisfaction with the level of analgesia. 


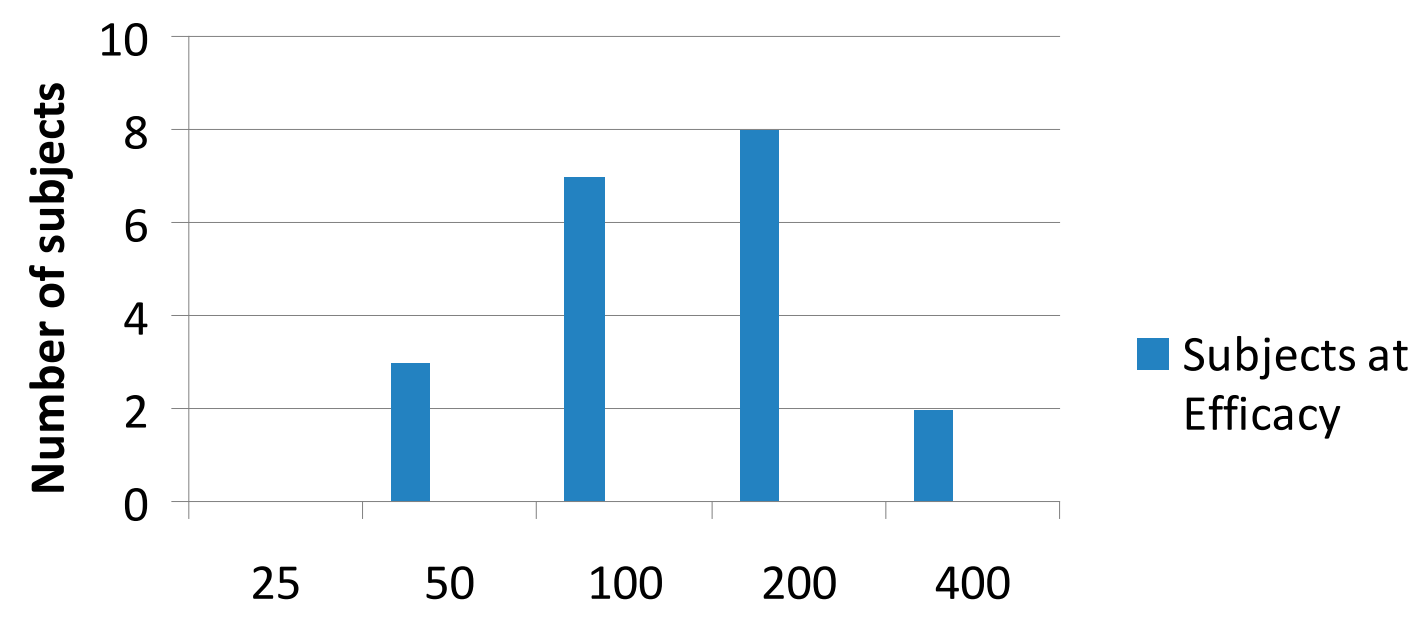

$\mu \mathrm{g} /$ day intrathecal morphine

Fig 2. Number of patients achieving satisfactory analgesia as a function of the dosage of intrathecal morphine.

increase significantly after the 12 month period (3.76 \pm 1.9 ) with a range of follow-up being 12-44 months. Based upon VAS during the trial, a dose response relationship was established (Fig. 1).

\section{Dose}

All individual final patient doses upon the completion of the trial are plotted in Fig. 1. The lowest dose at which efficacy was found was $50 \mu \mathrm{g} / \mathrm{d}$ of intrathecal morphine (Fig. 2) with the average dose being approximately $140 \mu \mathrm{g} / \mathrm{d}$. The average dose at 12 months was $335 \mu \mathrm{g} / \mathrm{d}$ at a concentration of $2 \mathrm{mg} / \mathrm{mL}$ preservativefree morphine, allowing greater than 90 days between refills. No patients are currently receiving oral opioid supplementation.

\section{Functional assessment during intrathecal trial}

Independent evaluation of functional status and improvement was obtained by physical and occupational therapists evaluating patients on the following criteria: VAS at rest, moving from supine to sitting position, sitting to standing, with ambulation, dressing lower body, picking up objects from the floor, and reaching overhead. VAS for each activity monitored, and for each dose of intrathecal morphine, were obtained for all patients throughout their trial. As efficacy was achieved, the dose titration stopped. Patient data was separated into groups based upon the final intrathe- cal dose at efficacy, average VAS scores, and standard deviation for all patients in each group were recorded. A one-way ANOVA and Mann-Whitney $U$ test of nonparametric data were utilized to determine statistical significance, which was set at $P<0.05$. For statistical analysis purposes, initial VAS scores served as a baseline from which VAS scores at efficacy were compared, allowing intra-group control comparisons. As noted in Tables 2a-d, pain scores with all assessments of activity were improved as a function of dose, compared to initial VAS obtained prior to starting the trial. Picking up an object from the floor was the most painful reported activity across the groups, but significant decreases in VAS were still achieved for this activity.

\section{Discussion}

We present a series of 20 consecutive patients with chronic noncancer pain currently being managed with an IDDS who were trialed and implanted utilizing a low-dose morphine protocol. This approach has produced 2 significant outcomes which are, in our opinion, noteworthy: 1) establishment and maintenance of efficacy at intrathecal morphine doses significantly lower than those previously reported in the literature and commonly reported in clinical practice $(1,9-11)$ and 2 ) the ability to achieve acceptable analgesia without oral opioid supplementation.

A review by Smith et al (9) presented the current state of our understanding with regard to opioid ef- 
Patient Selection and Outcomes Using a Low-Dose Intrathecal Opioid Trialing Method

Table $2 a$. Functional results from patients obtaining analgesia at $50 \mu \mathrm{g} / \mathrm{d}(\mathrm{n}=3)$. VAS scores at each trial dose with independent functional assessment ( $\mu \mathrm{g} / \mathrm{d}=$ dose of intrathecal morphine). ${ }^{*}=P<0.05$.

\begin{tabular}{|c|c|c|c|c|c|c|c|c|}
\hline \hline $\begin{array}{c}\text { VAS Reported by PT/ } \\
\text { OT During Trial }\end{array}$ & At Rest & $\begin{array}{c}\text { Supine to } \\
\text { Sitting }\end{array}$ & $\begin{array}{c}\text { Sitting } \\
\text { to } \\
\text { Standing }\end{array}$ & Gait & $\begin{array}{c}\text { Lower } \\
\text { Body } \\
\text { Dressing }\end{array}$ & $\begin{array}{c}\text { Picking } \\
\text { Up Object } \\
\text { From Floor }\end{array}$ & $\begin{array}{c}\text { Overhead } \\
\text { Reaching }\end{array}$ & $\begin{array}{c}\text { Overall } \\
\text { VAS at } \\
\text { Efficacy }\end{array}$ \\
\hline Initial & $7.2 \pm 1.1$ & $7.9 \pm 0.5$ & $7.2 \pm 0.9$ & $6.7 \pm 1.0$ & $7.1 \pm 0.4$ & $7.9 \pm 1.1$ & $7.6 \pm 1.2$ & $\mathrm{n}=0$ \\
\hline $25 \mu \mathrm{g} / \mathrm{d}(\mathrm{n}=20)$ & $5.1 \pm 1.2$ & $4.2 \pm 0.4$ & $5.8 \pm 0.4$ & $5.3 \pm 1.2$ & $5.8 \pm 0.8$ & $6.1 \pm 0.2$ & $6.3 \pm 0.8$ & $\mathrm{n}=0$ \\
\hline $50 \mu \mathrm{g} / \mathrm{d}(\mathrm{n}=19)$ & $2.8 \pm 1.6^{*}$ & $2.0 \pm 0.2^{*}$ & $1.1 \pm 0.2^{*}$ & $1.8 \pm 0.5^{*}$ & $1.9 \pm 0.7^{*}$ & $3.2 \pm 1.9^{*}$ & $1.1 \pm 0.4^{*}$ & $\mathrm{n}=3$ \\
$2.6^{*} \pm 1.3^{*}$ \\
\hline
\end{tabular}

Table 2b. Functional results from patients obtaining analgesia at $100 \mu \mathrm{g} / \mathrm{d}(\mathrm{n}=7)$. VAS scores at each trial dose with independent functional assessment $(\mu \mathrm{g} / \mathrm{d}=$ dose of intrathecal morphine $) .{ }^{*}=P<0.05$

\begin{tabular}{|c|c|c|c|c|c|c|c|c||}
\hline $\begin{array}{c}\text { VAS Reported by PT/OT } \\
\text { During Trial }\end{array}$ & At Rest & $\begin{array}{c}\text { Supine } \\
\text { to } \\
\text { Sitting }\end{array}$ & $\begin{array}{c}\text { Sitting to } \\
\text { Standing }\end{array}$ & Gait & $\begin{array}{c}\text { Lower } \\
\text { Body } \\
\text { Dressing }\end{array}$ & $\begin{array}{c}\text { Picking } \\
\text { Up Object } \\
\text { From Floor }\end{array}$ & $\begin{array}{c}\text { Overhead } \\
\text { Reaching }\end{array}$ & $\begin{array}{c}\text { Overall } \\
\text { VAS at } \\
\text { Efficacy }\end{array}$ \\
\hline Initial & $7.8 \pm 0.1$ & $7.6 \pm 0.5$ & $7.4 \pm 1.1$ & $6.9 \pm 1.0$ & $7.2 \pm 0.3$ & $7.7 \pm 1.0$ & $7.5 \pm 0.2$ & $\mathrm{n}=0$ \\
\hline $25 \mu \mathrm{g} / \mathrm{d}(\mathrm{n}=20)$ & $6.9 \pm 1.6$ & $4.3 \pm 0.3$ & $5.8 \pm 0.8$ & $5.8 \pm 1.5$ & $5.9 \pm 0.6$ & $6.1 \pm 0.3$ & $6.4 \pm 1.0$ & $\mathrm{n}=0$ \\
\hline $50 \mu \mathrm{g} / \mathrm{d}(\mathrm{n}=19)$ & $5.8 \pm 1.6$ & $5.0 \pm 0.3$ & $4.1 \pm 2.2$ & $4.8 \pm 0.5$ & $4.7 \pm 1.7$ & $5.2 \pm 1.9$ & $4.1 \pm 0.7$ & $\mathrm{n}=0$ \\
\hline $100 \mu \mathrm{g} / \mathrm{d}(\mathrm{n}=17)$ & $2.8 \pm 0.9^{*}$ & $2.3 \pm 0.6^{*}$ & $1.8 \pm 1.2^{*}$ & $2.8 \pm 0.2^{*}$ & $2.2 \pm 0.6^{*}$ & $2.8 \pm 1.8^{*}$ & $1.8 \pm 0.5^{*}$ & $\mathrm{n}=7$ \\
\hline
\end{tabular}

Table 2c. Functional results from patients obtaining analgesia at $200 \mu \mathrm{g} /$ day ( $n=8)$. VAS scores at each trial dose with independent functional assessment ( $\mu \mathrm{g} /$ day $=$ dose of intrathecal morphine $) .{ }^{*}=P<0.05$.

\begin{tabular}{|c|c|c|c|c|c|c|c|c||}
\hline $\begin{array}{c}\text { VAS Reported by } \\
\text { PT/OT During } \\
\text { Trial }\end{array}$ & At Rest & $\begin{array}{c}\text { Supine } \\
\text { to } \\
\text { Sitting }\end{array}$ & $\begin{array}{c}\text { Sitting to } \\
\text { Standing }\end{array}$ & Gait & $\begin{array}{c}\text { Lower } \\
\text { Body } \\
\text { Dressing }\end{array}$ & $\begin{array}{c}\text { Picking Up } \\
\text { Object From } \\
\text { Floor }\end{array}$ & $\begin{array}{c}\text { Overhead } \\
\text { Reaching }\end{array}$ & $\begin{array}{c}\text { Overall } \\
\text { VAS at } \\
\text { Efficacy }\end{array}$ \\
\hline Initial & $7.3 \pm 1.0$ & $7.8 \pm 0.7$ & $7.3 \pm 0.6$ & $7.4 \pm 1.2$ & $7.7 \pm 1.4$ & $7.2 \pm 0.8$ & $7.5 \pm 0.9$ & $\mathrm{n}=0$ \\
\hline $25 \mu \mathrm{g} / \mathrm{d}(\mathrm{n}=20)$ & $6.1 \pm 1.0$ & $5.8 \pm 0.8$ & $5.9 \pm 2.4$ & $5.8 \pm 0.1$ & $5.9 \pm 1.8$ & $6.9 \pm 2.2$ & $4.8 \pm 2.8$ & $\mathrm{n}=0$ \\
\hline $50 \mu \mathrm{g} / \mathrm{d}(\mathrm{n}=19)$ & $3.2 \pm 0.2$ & $4.0 \pm 1.2$ & $4.1 \pm 2.2$ & $3.8 \pm 2.5$ & $4.6 \pm 1.7$ & $5.2 \pm 1.9$ & $5.1 \pm 2.4$ & $\mathrm{n}=0$ \\
\hline $100 \mu \mathrm{g} / \mathrm{d}(\mathrm{n}=17)$ & $2.8 \pm 1.9$ & $3.8 \pm 0.6$ & $2.8 \pm 0.8$ & $3.2 \pm 0.3$ & $2.9 \pm 0.6$ & $3.8 \pm 2.6$ & $1.8 \pm 2.6$ & $\mathrm{n}=7$ \\
\hline $200 \mu \mathrm{g} / \mathrm{d}(\mathrm{n}=10)$ & $1.1 \pm 1.2^{*}$ & $1.9 \pm 1.5^{*}$ & $2.5 \pm 1.1^{*}$ & $2.2 \pm 0.9^{*}$ & $1.8 \pm 1.3^{*}$ & $3.8 \pm 2.6^{*}$ & $1.4 \pm 1.2^{*}$ & $\mathrm{n}=8$ \\
$2.1 \pm 0.9^{*}$ \\
\hline
\end{tabular}

Table $2 d$. Functional results from patients obtaining analgesia at $400 \mu \mathrm{g} / \mathrm{d}$ ( $\mathrm{n}=2$; average VAS without standard deviation). VAS scores at each trial dose with independent functional assessment $\left(\mu \mathrm{g} / d=\right.$ dose of intrathecal morphine). ${ }^{*}=P<0.05$.

\begin{tabular}{|c|c|c|c|c|c|c|c|c||}
\hline $\begin{array}{c}\text { VAS Reported by } \\
\text { PT/OT During Trial }\end{array}$ & At Rest & $\begin{array}{c}\text { Supine to } \\
\text { Sitting }\end{array}$ & $\begin{array}{c}\text { Sitting to } \\
\text { Standing }\end{array}$ & Gait & $\begin{array}{c}\text { Lower } \\
\text { Body } \\
\text { Dressing }\end{array}$ & $\begin{array}{c}\text { Picking Up } \\
\text { Object From } \\
\text { Floor }\end{array}$ & $\begin{array}{c}\text { Overhead } \\
\text { Reaching }\end{array}$ & $\begin{array}{c}\text { At } \\
\text { Efficacy }\end{array}$ \\
\hline Initial & 7.8 & 7.9 & 7.8 & 7.6 & 7.6 & 7.9 & 7.1 & $\mathrm{n}=0$ \\
\hline $25 \mu \mathrm{g} / \mathrm{d}(\mathrm{n}=20)$ & 7.1 & 6.9 & 6.9 & 6.9 & 7.1 & 7.4 & 6.9 & $\mathrm{n}=0$ \\
\hline $50 \mu \mathrm{g} / \mathrm{d}(\mathrm{n}=19)$ & 4.8 & 5.1 & 5.1 & 5.2 & 5.6 & 5.0 & 5.2 & $\mathrm{n}=0$ \\
\hline $100 \mu \mathrm{g} / \mathrm{d}(\mathrm{n}=17)$ & 4.8 & 4.8 & 4.9 & 4.2 & 4.3 & 4.9 & 4.8 & $\mathrm{n}=0$ \\
\hline $200 \mu \mathrm{g} / \mathrm{d}(\mathrm{n}=10)$ & 4.1 & 4.2 & 4.1 & 4.2 & 4.8 & 4.6 & 4.2 & $\mathrm{n}=0$ \\
\hline $400 \mu \mathrm{g} / \mathrm{d}(\mathrm{n}=2)$ & $0.5^{*}$ & $1.1^{*}$ & $2.1^{*}$ & $1.1^{*}$ & $2.2^{*}$ & $3.4^{*}$ & $1.2^{*}$ & $\mathrm{n}=2$ \\
\hline
\end{tabular}


ficacy in noncancer pain. Regarding intrathecal morphine therapy, this report focused on 5 studies with the number of participants ranging between 11 and 38 (12-16). Most participants in these studies were followed for approximately 2 years. In these reports intrathecal morphine was shown to have a pronounced analgesic effect that waned over the study period, but was still reported as significantly improved when compared to pre-implantation baseline pain scores. None of these studies focused on the trialing technique or dosing schedule as most were a titration to efficacy. Within several of the reviewed studies, the trialing technique varied between inpatient/ outpatient, and intrathecal versus epidural catheter trials (17). The current study size is comparable to these established benchmark studies and is somewhat unique in that it establishes a protocol for the trialing technique. Since other trialing techniques appear to achieve acceptable pain control, the real value of the current report may be in the ability to compare patient interaction with intrathecal therapy against an established norm within our center. For instance, we frequently see little efficacy at the starting dose but usually begin to see analgesia that is progressive in the 50-100 $\mu \mathrm{g} / \mathrm{d}$ range. We have found it is important during the trialing phase to keep the patient unaware of what our expected norms are to prevent bias from interfering with the trial outcome. The current data suggest that most patients will achieve analgesia in the 100-200 $\mu \mathrm{g} / \mathrm{d}$ of morphine dose-range, allowing possible dose-response relationships to be evaluated.

Presently we are unaware of any data which suggest a dose-response relationship in humans for intrathecal morphine has been established. Anderson and Burchiel (12) present a dose escalation relationship over 25 months with patients starting at approximately 2.5 $\mathrm{mg} / \mathrm{d}$ of intrathecal morphine and progressing to approximately $12 \mathrm{mg} / \mathrm{d}$ to presumably maintain analgesia (10). Additionally, in this study no attempts were made to regulate systemic opioid intake. Interestingly several patients were able to gradually discontinue their systemic opioid regimen, however at least $30 \%$ of them continued to need both intrathecal and oral opioids. In contrast, Deer et al (17) report a trend toward reduction of oral opioid intake, but were unable to achieve oral opioid cessation. In contrast, the current study is the first to report oral opioid cessation without return to systemic intake.

While oral opioids have been a mainstay in chronic pain management for years and are generally well tolerated with careful patient selection and monitoring, there are co-morbidities which limit the usefulness of the therapy (18). Opioid tolerance is a common cause for loss of oral opioid efficacy, while opioid-induced hyperalgeisa to a lesser extent may be responsible for loss of opioid efficacy (18). It is possible that the opioidfree interval in the current protocol, coupled with the administration of intrathecal opioid in low doses (micrograms per day) may reverse and limit the re-establishment of tolerance. This is evidenced by the modest or absent dose escalation seen in patients on this protocol. The length of time needed to reverse opioid tolerance and hyperalgesia is currently unknown. Pud et al (19) found that hyperalgesia to the cold pressor test in opioid addicts was not reversible in 4 weeks. However Compton et al (20) and Hay et al (21) report reversibility of hyperalgesia at 6 months. This suggests that tolerance and hyperalgesia can be reversed; the time interval necessary or the pharmacologic manipulations which enhance this are, however, not well understood.

It has been reported that low doses of systemic opioids (microgram range) may induce a hyperalgesic state. This finding has been proposed as a possible mechanism for the observation of significantly increased pain experienced during opioid taper (22). While the increase in pain is usually attributed to lessening analgesia with opioid withdrawal, the induction of a hyperalgesic state as opioid levels decrease has also been attributed to a paradoxical, low-dose opioid effect translated via the opioid receptor itself (22). This is in contrast to the opioid-induced hyperalgesic state which generally has been attributed to the interplay between the N-methyl-D-aspartate receptor and the opioid receptor via a Protein Kinase C-mediated mechanism $(22,23)$. In our hands, opioid in the lower microgram range was profoundly analgesic, suggesting that the low-dose opioid observations may be a systemic phenomenon that can be avoided by intrathecal administration. In addition, the significant analgesia obtained in our study using microgram dosing was at least comparable, and in some cases superior, to the analgesia obtained in similar studies which utilize intrathecal and systemic opioid combinations at much higher doses (10-17).

This finding is significant because of the recent reports of deaths following IDDS implantation secondary to opioid-induced respiratory depression (24). These reported adverse events following implantation of an IDDS occurred at doses in the $\mathrm{mg} / \mathrm{d}$ range with the lowest dose being $0.75 \mathrm{mg} / \mathrm{d}$ of intrathecal morphine, usually in combination with systemic opioids (24). Throughout most of the available literature, the 0.75 
$\mathrm{mg} / \mathrm{d}$ starting dose, which was the lowest dose at which mortality occurred in the Coffey study (24), would be sub-optimal for most patients to obtain analgesia (1). It was also suggested that titration to efficacy following implantation of the IDDS, despite the known dosage levels from an intrathecal trial, should be done cautiously (24). This seems wise in the setting of a newly implanted IDDS in a patient continuing oral opioid therapy that, concomitantly, can self-escalate their oral opioid intake. The current protocol establishes efficacy well below the recommended lower range starting dose in the study by Coffey (24).

Patient acceptance of the opioid taper and the opioid-free interval is a potential area of concern for many clinicians. In our practice, IDT is suggested after oral opioids and other interventional modalities have failed to achieve lasting desired results. As such, patients are somewhat aware that oral opioid dose escalation has not been successful. Of the patients trialed using this protocol, most reported that they could tell no difference between their VAS scores while taking oral opioids and after stabilization in the opioid-free interval prior to the intrathecal trial. Anecdotally, and consistent with the low-dose systemic hyperalgesia theory (22), many patients did report a significant increase in pain at or near the completion of the opioid taper, which returned to baseline by the time the patient was ready for the inpatient intrathecal trial (data not included). All patients in the current study reported pain scores that were essentially identical on and off oral opioid therapy. This anecdotal finding is in agreement with the findings of Trescott et al (16) in the meta-analysis examining the effectiveness of oral opioid therapy. In this review it was determined that many patients do not achieve long-term analgesia with oral opioids. The current protocol selects patients who have failed oral opioid therapy and provides an alternative route of administration with excellent attainment of analgesia.

Another aspect of the Trescot meta-analysis which is troubling is the lack of increase in functional capacity with oral opioid therapy (18). It appears based on those findings that achieving analgesia with oral opioids may not return the patient to a more functional state. In contrast, most studies of intrathecal therapy report an increase in functional capacity (17). In our study patients were observed to have improved function as assessed by physical and occupation therapists as a function of VAS while performing activities such as sitting, standing, walking 100 and 400 yards, and range of motion evaluation of lower extremities during the intrathecal trial. The physiologic mechanism behind improvement is not entirely clear; however, a decrease in hyperalgesic state could reasonably be possible. Currently we are conducting further investigation into the potential for long-term increased functional capacity using this approach to intrathecal therapy. Further, prospective studies with regard to the presence of hyperalgesia comparing patients on this low-dose protocol with those on traditional oral therapy alone or in combination with intrathecal opioid will also be necessary.

Regarding the cost of therapy, several groups have reported that IDT does have some cost savings potential (25-27). Looking at financial models taking into account current costs and reimbursements, it has been suggested that IDT over the course of 6-10 years may be cheaper than treatment with common combinations of non-generic or brand-name on-patent medications. In this same comparison, however, it was noted that treatment with generic medication provided potential cost savings. The authors also correctly point out that in most cases, patients are on a combination of oral medications (generic and brand-name) in addition to IDT, thus complicating any easy comparisons of cost in real-world settings. In contrast, the current study does allow the Deer et al (2) comparisons to be valid as no patients are maintained on oral opioids in combination with their IDT. While patients do frequently continue adjunctive medications for muscle spasm or neuropathic pain, the additional cost of oral opioids are avoided. It has been estimated that the 10-year cost of intrathecal monotherapy with morphine is approximately $\$ 93,000.00$ based on a $6 \mathrm{mg} / \mathrm{d}$ morphine administration (2). While the amount of drug compounded for administration is a miniscule component of the cost, the choice of $6 \mathrm{mg} / \mathrm{d}$ as a reasonable daily dose in the Deer intrathecal guidelines underscores the novelty of our findings that efficacy can be achieved at significantly lower doses (2).

Limitations of this study are the small patient size and the retrospective nature of the design. However, both of these limitations are present throughout the comparable literature in this area because prospective long-term efficacy studies are difficult to perform in pain management. Despite these difficulties, longterm trials with the ability for patients to cross over are needed to accurately provide data about the efficacy of oral opioid therapy, traditional combination intrathcecal/oral opioid therapy, and the current low-dose morphine protocol. 


\section{Conclusion}

In conclusion, we report the achievement of significant analgesic efficacy which is sustained for at least an average of 18 months. Additionally, this maintenance analgesia is obtained utilizing doses of intrathecal morphine significantly lower than the starting doses reported in other studies. We believe this represents an advancement which will enhance patient satisfaction, reduce cost, and improve safety. Additionally, we suggest that these data may represent the first human dose-response relationships in patients with chronic noncancer pain.

\section{Acknowledgments}

The authors would like to recognize William 0 Witt MD, Chair Emeritus and founding director of the University of Kentucky Pain Program for first articulating the concept of low-dose intrathecal therapy.

\section{References}

1. Wallace $M$ and Yaksh TL. Long-term spinal analgesic delivery: A review of the preclinical and clinical literature. Reg Anesth Pain Med 2000; 25:117-157.

2. Deer TR, Smith HS, Cousins M, Doleys DM, Levey RM, Rathmel JP, Staats PS, Wallace M, Webster LR. Consensus guidelines for the selection and implantation of patients with noncancer pain for intrathecal drug delivery. Pain Phys 2010; 13:E175-E213.

3. Deer TR, Krames ES, Hassenbusch SG, Burton A, Caraway D, DuPen S, Eisenach J, Erdeck M, Grigsby E, Kim P, Levy R, McDowell G, Mekhail N, Panchal S, Prager J, Rauch R, Saulino M, SItzman T, Staats P, Stanton-Hicks M, Stearns L, Willis KD, Witt WO, Follett K, Huntoon $M$, Liem L, Rathmell J, Wallace M, Buchser E, Cousins M, Ver Donck A. ARTICLE TITLE? Neuromodulation 2007; 10:300328.

4. Grider JS, Harned ME, Sloan PA. Patient selection and trialing techniques utilizing low-dose intrathecal morphine for chronic nonmalignant pain: a report of two cases. J Opioid Manag 2010; 6:371376.

5. Witt WO, Richardson WB. Intrathecal low-dose morphine; case study 3 and 4. Synchromed 2 programmable infusion system. Product Bulletin. Minneapolis, MN: Medtronic Neuromodulation; 2010.

6 American Society of Anesthesiologists Task Force on Neuraxial Opioids, Horlocker TT, Burton AW, Connis RT, Hughes SC, Nickinovich DG, Palmer CM, Pollock JE, Rathmell JP, Rosenquist RW, Swisher JL, Wu CL. Practice guidelines for the prevention, detection, and management of respiratory depression associated with neuraxial opioid administration. Anesthesiology 2009; 110:218-
230.

7. Grider JS, Brown RE, Colclough GE. Perioperative management of patients with an intrathecal drug delivery system for chronic pain. Anesth Analg 2008; 107:1393-1396.

8. Williamson A. Pain: A review of three commonly used pain rating scales. Issues Clin Nur 2005; 14:798-804.

9. Smith HS, Deer TR, Staats PS, Singh V, Sehgal N, Cordner H. Intrathecal drug delivery. Pain Physician 2008; 11:S89$\mathrm{S} 104$.

10. Hayek SM, Deer TR, Pope JE, Panchal S), Patel VB. Intrathecal therapy for cancer and non-cancer pain. Pain Physician. 2011; 14:219-248.

11. Deer TR, Smith HS, Cousins M, Doleys DM, Levy RM, Rathmell JP, Staats PS, Wallace M, Webster LR.Consensus guidelines for the selection and implantation of patients with noncancer pain for intrathecal drug delivery. Pain Physician 2010; 13:E175-E213.

12. Anderson VC, Burchiel KJ. A prospective study of long-term intrathecal morphine in the management of chronic nonmalignant pain. Neurosurgery 1999; 44:289300.

13. Angel IF, Gould HJ, Carey ME. Intrathecal morphine pump as treatment option in chronic pain of nonmalignant origin. Surg Neurol 1998; 49:92-99.

14. Hassenbusch SJ, Stanton-Hicks M, Covington EC, Walsh JG, Guthery DS. Longterm intraspinal infusions of opioids in the treatment of neuropathic pain. J Pain Symptom Manage 1995; 10:527-543.

15. Kumar K, Kelly M, Pirlot T. Continuous intrathecal morphine treatment for chronic pain of nonmalignant etiology: Long-term benefits and efficacy. Surg Neurol 2001; 55:79-86.
16. Thimineur MA, Kravitz K, Vodapollay MS. Intrathecal opioid treatment for chronic non-malignant pain: A 3-year prospective study. Pain 2004; 109:242249.

17. Deer T, Chapple I, Classen A, Javery K, Stoker V, Tonder L, Burchiel K. Intrathecal drug delivery for treatment of chronic low back pain: report from the national outcomes registry for low back pain. Pain Med 2004; 5:6-13.

18. Trescot A, Glaser SE, Hansen H, Benyamin R, Patel S, Manchikanti L. Effectiveness of opioids in the treatment of non-cancer pain. Pain Physician 2008; 11:S181-S200.

19. Pud D, Cohen D, Lowental E, Eisenburg E. Opioids and abnormal pain perception: New evidence from a study of chronic opioid addicts and healthy subjects. Drug Alc Dep 2006; 82:218-223.

20. Compton P, Charuvastra C, Kintaudi K, Ling W. Pain responses in methadonemaintained opioid abusers. J Pain Symptom Manage 2000; 20:237-245.

21. Hay JL, White JM, Somogyi AA, Bochner F, Rounsefell B, Demple T. Clinical evidence for opioid-induced hyperalgeisa. Proceedings of the Australasian Society of Clinical and Experimental Pharmacologists and Toxicologists 2003; 10:4.

22. Chu LF, Angst MS, Clark D. Opioid-induced hyperalgesia in humans: Molecular mechanisms and clinical considerations. Clin J Pain 2008; 24:479-496.

23. Grider JS, Ackerman WE. Opioid-induced hyperalgesia and tolerance: Understanding opioid side effects. Expert Rev Clin Pharmacol 2008; 1:291-297.

24. Coffey RJ, Owens ML, Broste SK, Dubois MY, Ferrante MF, Schultz DM, Stearns LJ, Turner MS. Mortality associated with implantation and management of intrathecal drug infusion systems to treat 
chronic non-cancer pain. Anesthesiology 2009; 11:881-891.

25. Bedder MD, Burchiel K, Larson A. Cost analysis of two implantable narcotic delivery systems. J Pain Symptom Mange 1991; 6:368-373.

26. De Lissovoy G, Brown RE, Halpern M,
Hassenbusch SJ, Ross E. Cost-effectiveness of long-term intrathecal morphine therapy for pain associated with failed back surgery syndrome. Clin Ther 1997; 19:96-112.

27. Kumar K, Hunter G, Demeria DD. Treatment of chronic pain by using intrathe- cal drug therapy compared with conventional pain therapies: A cost-effectiveness analysis. J Neurosurg 2002; 97:803810. 
